\title{
History of Oilseed Rape Cropping and Geographic Origin Affect the Genetic Structure of Plasmodiophora brassicae Populations
}

\author{
Becke Strehlow, Friederike de Mol, and Christine Struck
}

Group Crop Health, Faculty of Agricultural and Environmental Sciences, University of Rostock, Satower Str. 48, 18059 Germany. Accepted for publication 5 November 2013.

\begin{abstract}
Strehlow, B., de Mol, F., and Struck, C. 2014. History of oilseed rape cropping and geographic origin influence the genetic structure of Plasmodiophora brassicae populations. Phytopathology 104:532-538.

The soilborne pathogen Plasmodiophora brassicae causes clubroot on Brassica crops, a common disease in many oilseed rape growing regions. Here, we investigate genetic diversity and geographic differentiation of $P$. brassicae populations from different regions in Germany. We compared three regions that differ in oilseed rape cropping history, oilseed rape acreage, and incidence of clubroot. These regions were either spatially separated or separated by the former inner German border. Plasmodiophora isolates were collected from 59 fields $(29,17$, and 13 fields per region, respectively) and 174 amplified fragment length polymorphism (AFLP) markers were analyzed. Every field isolate showed a unique

(gene diversity, genotypic diversity, and linkage disequilibrium) between the regions does not support our hypotheses that cropping history, oilseed rape acreage, and incidence of clubroot affect these estimates. Principal component analysis (PCA), fixation index $\left(F_{\mathrm{ST}}\right)$, and generalized linear model (GLM) were suitable to specify regional differences. PCA revealed two clusters of isolates based on the geographic origin of the isolates and $F_{\text {ST }}$ showed that these clusters were highly differentiated. Hypotheses about association of genotypes with different spatial scales were tested with GLM: the region, reflecting the cropping history, and the individual field had a significant effect on the AFLP pattern. We propose that individual field isolates represent a discrete population and that geographic differentiation results from low levels of gene flow due to the limited dispersal of this soilborne pathogen and from localized selection pressure as unifying force on the genotypes.
\end{abstract} genotype pattern; that is, no genotype was shared among the regions and different fields. The mean gene diversity was 0.27 , suggesting that $P$. brassicae is a genetically diverse species. The comparison of indexes
Additional keywords: genetic differentiation.
Clubroot disease, caused by the soilborne, obligate plant pathogen Plasmodiophora brassicae, is an economically important disease of cruciferous crops, including oilseed rape. Clubroot is known to occur in $>60$ countries and to be present on 3.5 to $10 \%$ of the land used for host plants worldwide (11). In Germany, the impact of clubroot on oilseed rape has been greatest in regions in which oilseed rape production predominates, particularly in the northern part of the country. In these regions, the disease prevalence is 10 to $20 \%$ of the cropland used for oilseed rape (NPZ-Lembke, Plant Breeding Company, Germany, unpublished data). Chemical control of the pathogen is not possible at present and cultural practices can only limit the infestation with $P$. brassicae (12). Therefore, the development of resistant cultivars is considered the most economical and efficient method for clubroot control (10). Successful development of durable plant resistance requires an understanding of the genetic structure of the pathogen population because this knowledge provides insight into the evolutionary potential of a pathogen, such as the potential to break down the resistance of crops (37). Genetic structure is the extent of genetic variability and its distribution within and among pathogen populations. The two most important characteristics that define the genetic structure are the reproduction system and the amount of gene or genotype flow (38). Genetic variability can change at different stages in the life cycle of $P$. brassicae (49): (i) during nuclear division of the plasmodia in the root hair (primary plasmodia) and the cortical tissues (secondary plasmodia), (ii) during meiotic cleavage in the secondary plasmodia $(6,19)$, and

Corresponding author: B. Strehlow; E-mail address: becke.strehlow@uni-rostock.de

http://dx.doi.org/10.1094/PHYTO-07-13-0210-R

(C) 2014 The American Phytopathological Society (iii) during fusion of secondary zoospores to binucleate zoospores (26). There are still uncertainties about the importance of sexual and asexual reproduction in the life cycle of $P$. brassicae (28). Individuals of $P$. brassicae are distributed as resting spores with infested soil through erosion, carried on farm machinery and other equipment (12), or with surface-contaminated seed or tubers (44). This human-induced movement should be the most important source for gene or genotype flow within and between $P$. brassicae populations in different geographic regions.

$P$. brassicae populations in Europe display great genetic and pathogenic variation $(34,46)$ but the genetic basis of these differences is unknown. Pathogenicity-based classifications differentiate field isolates and were used to describe the pathogenic variation of isolates in France (46), Canada (47), Australia (13), and Japan (30). Despite the value of these pathotype data, the use of virulence phenotypes to investigate genetic variation has several important limitations. Few genetic methods have been developed to define the extent of genetic variation of $P$. brassicae $(7,29$, 40,42). The main objectives of these molecular approaches were to detect genomic polymorphism directly related to pathotype classification. These studies compare either single spore isolates from a single root gall or a small number of selected field isolates $(17,18,29,34)$. Up to now, there have been no population genetic studies combined with statistical analyses to detect genetic diversity and genetic structure of Plasmodiophora field isolates.

In the present study, genetic variability among Plasmodiophora field isolates of three regions in Germany were detected by amplified fragment length polymorphism (AFLP) technique. The three sampling sites differ in oilseed rape cropping history, oilseed rape acreage, and incidence of clubroot. The regions are either spatially separated or were isolated by the former inner German 
border. We expected that high oilseed rape acreage combined with long-established Plasmodiophora populations within the traditional oilseed rape regions would lead to higher gene diversity compared with the region where oilseed rape was introduced $\approx 25$ years ago. The distribution of $P$. brassicae resting spores between these regions is unlikely and this limited exchange should have caused genetic differentiation. The objectives of this population genetic study were to (i) assess the level of genetic diversity of the $P$. brassicae field isolates, (ii) determine the genetic structure of isolates, and (iii) test hypotheses about association of the genetic structure with spatial components. The data reported here provide the first insight into pathogen diversity and population structure of $P$. brassicae on a molecular basis using AFLP.

\section{MATERIALS AND METHODS}

P. brassicae isolates. Fifty-nine field isolates of $P$. brassicae were obtained from three different regions in Germany (Fig. 1) First of all, the sampling sites were selected according to oilseed rape cropping history, oilseed rape acreage, and incidence of clubroot. Region 1 and region 2 in North Germany are traditional oilseed rape cropping areas and oilseed rape has been cultivated since 1850 on $\approx 20 \%$ of the arable land (3). In contrast to these regions, in the third sampling site in South Germany, oilseed rape became more important 20 to 30 years ago, and $<15 \%$ of the arable land was cropped with oilseed rape (3) (Table 1). The regions in North Germany share related environmental conditions and cropping systems and the incidence of clubroot is high (10 to
$20 \%$ of the oilseed rape acreage) (NPZ-Lembke, plant breeding company, unpublished data). Fields highly infested with clubroot in region 3 were detected on 1 to $2 \%$ of the oilseed rape acreage (NPZ-Lembke, plant breeding company, unpublished data) (Table 1). These three regions are separated by geographic distance (region 1 and region 2 from region 3 ) or by limited exchange for 40 years during the political division of Germany from 1949 to 1989 (region 1 from region 2) (Fig. 1).

Each field isolate consisted of infected oilseed rape roots or soil samples. The plant and soil material was sampled in the years 2009, 2011, and 2012. Clubbed roots were kept at $4^{\circ} \mathrm{C}$ and the soil was air dried and stored at room temperature. For propagation of P. brassicae isolates, Brassica napus cultivar Oase plants were inoculated with $4 \mathrm{ml}$ of spore suspension $\left(10^{7}\right.$ spores $\left./ \mathrm{ml}\right) 4$ days after sowing or directly sown in the infested soil sample. Plants were cultivated in the greenhouse $\left(21\right.$ and $18^{\circ} \mathrm{C}$, day and night, respectively, with a $16-\mathrm{h}$ photoperiod) and root galls were har-

TABLE 1. Characteristics of the sampling sites (regions 1, 2, and 3)

\begin{tabular}{|c|c|c|c|}
\hline \multirow[b]{2}{*}{ Characteristics } & \multicolumn{3}{|c|}{ Region } \\
\hline & 1 & 2 & 3 \\
\hline Oilseed rape-cropping history & Since 1850 & Since 1850 & Since 1980 \\
\hline Oilseed rape acreage $(\%)^{\mathrm{a}}$ & $15-20$ & $20-25$ & $5-15$ \\
\hline Highly infested clubroot fields $(\%)^{\mathrm{b}}$ & $\approx 10$ & $\approx 20$ & $1-2$ \\
\hline Sampled field isolates $(n)$ & 29 & 17 & 13 \\
\hline
\end{tabular}

a Years 2003 to 2013 (3).

b NPZ-Lembke, Plant Breeding Company, unpublished data.

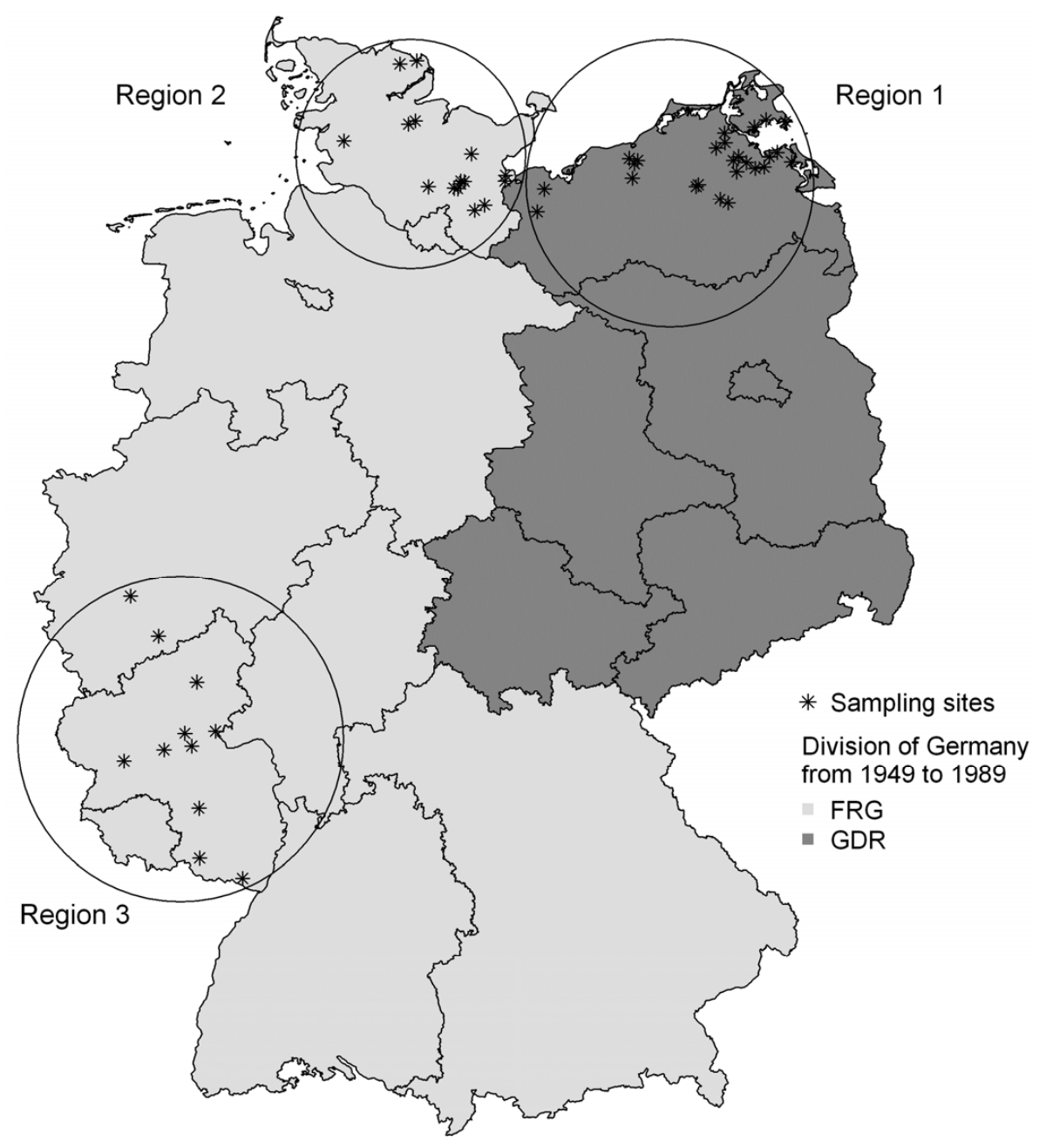

Fig. 1. Sampling sites of Plasmodiophora field isolates and political division of Germany from 1949 to 1989 into Federal Republic of Germany (FRG) and German Democratic Republic (GDR). 
vested 7 weeks after inoculation. Two clubs from each field were taken for DNA fingerprinting.

Molecular genotypes: DNA isolation and AFLP analyses. DNA of each isolate was extracted from $100 \mathrm{mg}$ of galled roots by first grinding the frozen tissue with one steal bead (diameter of $0.7 \mathrm{~mm}$ ) in a homogenizer (Fa. Retsch, Germany) for $30 \mathrm{~s}$ until the tissue was pulverized, and second using the DNA plant mini kit (Fa. Peqlab, Germany). Between the homogenization steps, the tissue was kept in liquid nitrogen.

AFLP analyses were performed based on Vos et al. (51), with the following modifications. Genomic DNA samples (500 ng) were digested with $5 \mathrm{U}$ of TrulI and $12.5 \mathrm{U}$ of PstI enzymes in a total volume of $50 \mu \mathrm{l}$ for $3 \mathrm{~h}$ at $37^{\circ} \mathrm{C}$. DNA was ligated at $14^{\circ} \mathrm{C}$ over night after adding a mixture of $10 \mu \mathrm{l}$ consisting of MseIadapter at $5 \mathrm{pmol} / \mu \mathrm{l}, P$ stI-adapter at $0.5 \mathrm{pmol} / \mu \mathrm{l}$, and $2 \mathrm{U}$ of T4 DNA-ligase, followed by inactivation at $65^{\circ} \mathrm{C}$ for $10 \mathrm{~min}$. Preamplification was carried out on $1 \mu \mathrm{l}$ of ligated DNA (previously 1:10 diluted) using Pst $\mathrm{I}$ and $M s e \mathrm{I}$ primer without selective nucleotide as follows: $2 \mathrm{~min}$ at $94^{\circ} \mathrm{C} ; 30$ cycles at $94^{\circ} \mathrm{C}$ for $30 \mathrm{~s}$, $60^{\circ} \mathrm{C}$ for $60 \mathrm{~s}$, and $72^{\circ} \mathrm{C}$ for $60 \mathrm{~s}$; followed by $5 \mathrm{~min}$ at $70^{\circ} \mathrm{C}$. Polymerase chain reaction (PCR) with PstI and MseI primer with two or three selective nucleotides each were carried out on $1 \mu \mathrm{l}$ of preamplified product (previously 1:50 diluted) as follows: 2 min at $94^{\circ} \mathrm{C} ; 13$ cycles at $94^{\circ} \mathrm{C}$ for $30 \mathrm{~s}, 65^{\circ} \mathrm{C}$ for $60 \mathrm{~s}$ (decreasing temperature by $1{ }^{\circ} \mathrm{C}$ per cycle), and $72^{\circ} \mathrm{C}$ for $60 \mathrm{~s}$; followed by 23 cycles at $94^{\circ} \mathrm{C}$ for $30 \mathrm{~s}, 56^{\circ} \mathrm{C}$ for $60 \mathrm{~s}$, and $72^{\circ} \mathrm{C}$ for $60 \mathrm{~s}$; and final extension for $7 \mathrm{~min}$ at $70^{\circ} \mathrm{C}$. In total, 13 primer pair combinations from PstI-2/3 and $M s e \mathrm{I}-2 / 3$ were tested. The Pst $\mathrm{I}$ primer was fluorescently labeled with infrared dyes DY-681 or DY-781 (Biomers, Germany). A LI-COR 4300 DNA sequencer was used to obtain electropherograms following the manufacturer's instructions. Fluorescent AFLP patterns were scored manually for band presence $(=1)$ and band absence $(=0)$ to create binary matrices. Contamination with host DNA could not be excluded. Only reproducible bands of $P$. brassicae, clearly distinct from the host bands in the amplifications patterns, were scored and used for the genetic analysis. To ensure reproducibility, all AFLP profiles were generated in at least two independent assays using two independent DNA extractions.

Data analyses. The genetic diversity of the 59 AFLP genotypes was quantified on the basis of (i) percentage of polymorphic loci, (ii) Nei's gene diversity (41), and (iii) Stoddard and Taylor's index (21). Calculations of these estimates were performed with the R-script AFLPdat (15). Nei's gene diversity $(\hat{h})$ was estimated for each population according to each marker and then taking the average $(41)$ as $\hat{h}=n /(n-1) \times\left[1-\left(\right.\right.$ freq $(1)^{2}+$ freq $\left.\left.(0)^{2}\right)\right]$, where $n$ is the number of gene copies in the sample and freq( 1$)$ and freq( $(0)$ are the frequencies of band presence and band absence, respectively. Dominant markers can only produce two alleles at each locus. Therefore, the maximum value for gene diversity is 0.5 . It is maximized when the band presence and the band absence have equal frequencies. Bootstrapping was used to estimate the $95 \%$ confidence intervals for gene diversity $(\mathrm{nBoot}=1,000)$. To distinguish richness, evenness, and diversity between the regions and across the overall population, multilocus genotype diversity analyses was used (21). Genotypic diversity was calculated as Stoddard and Taylor's index $(G)$, where $G=1 /$ sum (genotype frequencies ${ }^{2}$ ).

Genotypic diversity refers to the number of genotypes in a population and its distribution within the population. Genotypic diversity increases with increasing number of genotypes and if no genotype dominates the population. $G$ is dependent on sample size; therefore, it was scaled by the number of observed genotypes $\left(g_{o b s}\right)$. The index of $G / g_{\text {obs }}$ was calculated as the index of evenness (frequency of genotypes) because the effect of genotype richness is removed. Genotype richness was expressed by the number of observed genotypes.

Genetic relationships were quantified on the basis of genetic distances. Jaccard's distance and Euclidean distance were calculated with the R package "vegan" by using the function "vegdist" (43). Genetic structure was graphically displayed by principal component analysis (PCA), performed by "dudi.pca" using the R package "ade4" based on a Euclidean distance matrix of the AFLP data (14).

Genetic differentiation was estimated on the basis of (i) a distance-based approach via analysis of molecular variance (AMOVA) and (ii) a model-based approach via generalized linear modeling (GLM). AMOVA was performed with the R package "ade4" (14). Pairwise values of fixation index $\left(F_{\mathrm{ST}}\right)$ were calculated via AMOVA using Arlequin version 3.1 (16). The $F_{\mathrm{ST}}$ value was, in turn, used to estimate gene flow as parameter of gene flow $(\mathrm{Nm})=$ $1 / 4\left[\left(1 / F_{\mathrm{ST}}\right)-1\right](35,56)$.

GLM was performed with the R package "mvabund" (53). We used the function "manyglm" and the function "anova.manyglm" with a log-likelihood ratio test statistic and the "pit.trap" resampling method with a high number of bootstrap samples (nBoot = $1,000)(54)$. The model was fitted with multilocus genotype as response variable and spatial components as explanatory factors. Spatial components were defined by fields, regions (region 1, region 2 , and region 3) and geographic origin (North and South Germany).

Linkage disequilibrium (LD) was calculated with the index of association $\left(I_{A}\right)$, and another measure of $\mathrm{LD}\left(r_{d}\right)$ using Multilocus $1.3 \mathrm{~b}$ (1). In the association tests, $I_{A}$ and $r_{d}$ are expected to be 0 if populations are freely recombining and $>0$ if there is association between alleles (1). $P$ values for divergence of random mating for both indices were performed with 1,000 randomizations.

\section{RESULTS}

Genetic diversity. The 13 primer combinations generated a total of 174 polymorphic AFLP loci and were clearly distinct from the host bands in the amplifications patterns. The size of the DNA fragments was 100 to $550 \mathrm{bp}$ and the number of amplified fragments was 5 to 21 fragments per primer combination. All AFLP profiles were fully reproducible in at least two independent assays using two independent DNA extractions. No genotype was shared among regions and different fields; every field isolate had a unique multilocus genotype pattern. By Stoddard and Taylor's index $G$, genotypic diversity was $100 \%$ of its maximum possible value on average in each region (Table 2). The percentage of

TABLE 2. Basic genetic properties of the Plasmodiophora field isolates from Germany

\begin{tabular}{|c|c|c|c|c|c|c|c|}
\hline Sampling site & $n$ & Frag $_{\text {pol }}{ }^{a}$ & Polymorphism (\%) & $\hat{h}^{\mathrm{b}}$ & $G^{\mathrm{c}}$ & $G / g_{o b s}{ }^{\mathrm{d}}$ & $D^{\mathrm{e}}$ \\
\hline Region 1 & 29 & 152 & 87 & 0.31 & 29 & 1 & 0.60 \\
\hline Region 2 & 17 & 135 & 76 & 0.24 & 17 & 1 & 0.56 \\
\hline Region 3 & 13 & 138 & 79 & 0.27 & 13 & 1 & 0.45 \\
\hline Total & 59 & 174 & 100 & 0.27 & 59 & 1 & 0.62 \\
\hline
\end{tabular}

${ }^{\mathrm{a}} \mathrm{Frag}_{\mathrm{pol}}=$ polymorphic fragments.

${ }^{\mathrm{b}} \hat{h}=$ Nei's gene diversity.

c $G=$ genotypic diversity.

${ }^{\mathrm{d}} \mathrm{G} / g_{\text {obs }}=$ evenness with $g_{\text {obs }}$, the number of observed genotypes.

e $D=$ genetic distance $=$ the weighted mean distance based on Jaccard's distance. 
polymorphic fragments was $87 \%$ in region $1,76 \%$ in region 2 , and $79 \%$ in region 3 . The mean gene diversity was moderate across the regions (0.27). Region 1 had the highest gene diversity (0.31) and differed little in gene diversity of region 2 and region 3 ( 0.24 and 0.27 , respectively). If compared on the level of geographic origin, the gene diversity in North Germany (region 1 and region 2) was slightly higher than the gene diversity in South Germany (region 3 ) (0.28 versus 0.27$)$.

LD. LD was high among all 59 AFLP genotypes, with an $I_{A}$ of 6.84 and an $r_{d}$ of $0.04(P<0.001)$. LD was also high between genotypes within each region. The 29 genotypes from region 1 had an $I_{A}$ of 7.18 and an $r_{d}$ of $0.05(P<0.001)$, the 17 genotypes from region 2 had an $I_{A}$ of 3.81 and $r_{d}$ of $0.03(P<0.001)$, and the 13 genotypes from region 3 had an $I_{A}$ of 19.4 and an $r_{d}$ of 0.14 $(P<0.001)$ (Table 3$)$.

Population structure. PCA revealed clusters of isolates with overlap (Fig. 2). Regions were not clearly separated but clusters of isolates indicated geographic structuring between the field isolates from North and South Germany. The first three coordinates explained 21,11 , and $9 \%$ of the variation. Field isolates of region 1 and region 2 from North Germany did not cluster

TABLE 3. Linkage disequilibrium between genotypes within the regions

\begin{tabular}{lrc}
\hline Region & \multicolumn{1}{c}{$I_{A}{ }^{\mathrm{a}}$} & \multicolumn{1}{c}{$r_{d}^{\mathrm{b}}$} \\
\hline 1 & $7.18^{* * *}$ & $0.05^{* * *}$ \\
2 & $3.81 * * *$ & $0.03 * * *$ \\
3 & $19.40^{* * *}$ & $0.14 * * *$ \\
Total & $6.84 * * *$ & $0.04 * * *$
\end{tabular}

a Index of association. $* P<0.05 ; * * P<0.01 ; * * * P<0.001$.

b Another measure of linkage disequilibrium. $* P<0.05$; $* * P<0.01$; $* * * P<$ 0.001 . separately. However, region 2 showed less overlap with region 3 than region 1.

Following the identification of the two clusters by PCA, we estimated the genetic distance for the geographic origin, North and South Germany, and for the regions themselves. Jaccard's distance among the field isolates was 0.08 to 0.83 (mean 0.62). The mean distances within North Germany (0.59) and South Germany (0.46) and between these geographic origins (0.68) indicated that field isolates sampled from the same geographic origin were genetically more similar to each other than field isolates from different geographic origins, confirming geographic clustering by PCA (Table 4). Field isolates of region 1 had a higher mean genetic distance than field isolates of region 2 and region 3 ( 0.6 versus 0.56 and 0.45 ) and the between-region genetic distance revealed that field isolates from region 1 and region 2 were less distinct from each other compared with field isolates from region 3 (0.61 versus 0.66 and 0.71 ) (Table 5).

Geographic differentiation. The overall $F_{\mathrm{ST}}$ for grouping isolates by geographic origin was 0.276 , with $24 \%$ of the AFLP variation between isolates from North Germany and South Germany, $3 \%$ of variation between region 1 and region 2 within North Germany, and $73 \%$ variation within the regions. The $\mathrm{Nm}$ between the fields was very low (0.65). Based on $F_{\mathrm{ST}}$, isolates from region 1 and region 2 were not differentiated for AFLP genotype, whereas both regions were significantly differentiated from region 3 at

TABLE 4. Genetic distances between field isolates from North and South Germany

\begin{tabular}{lcc}
\hline & North Germany & South Germany \\
\hline North Germany & 0.598 & 0.675 \\
South Germany & 0.675 & 0.455 \\
\hline
\end{tabular}
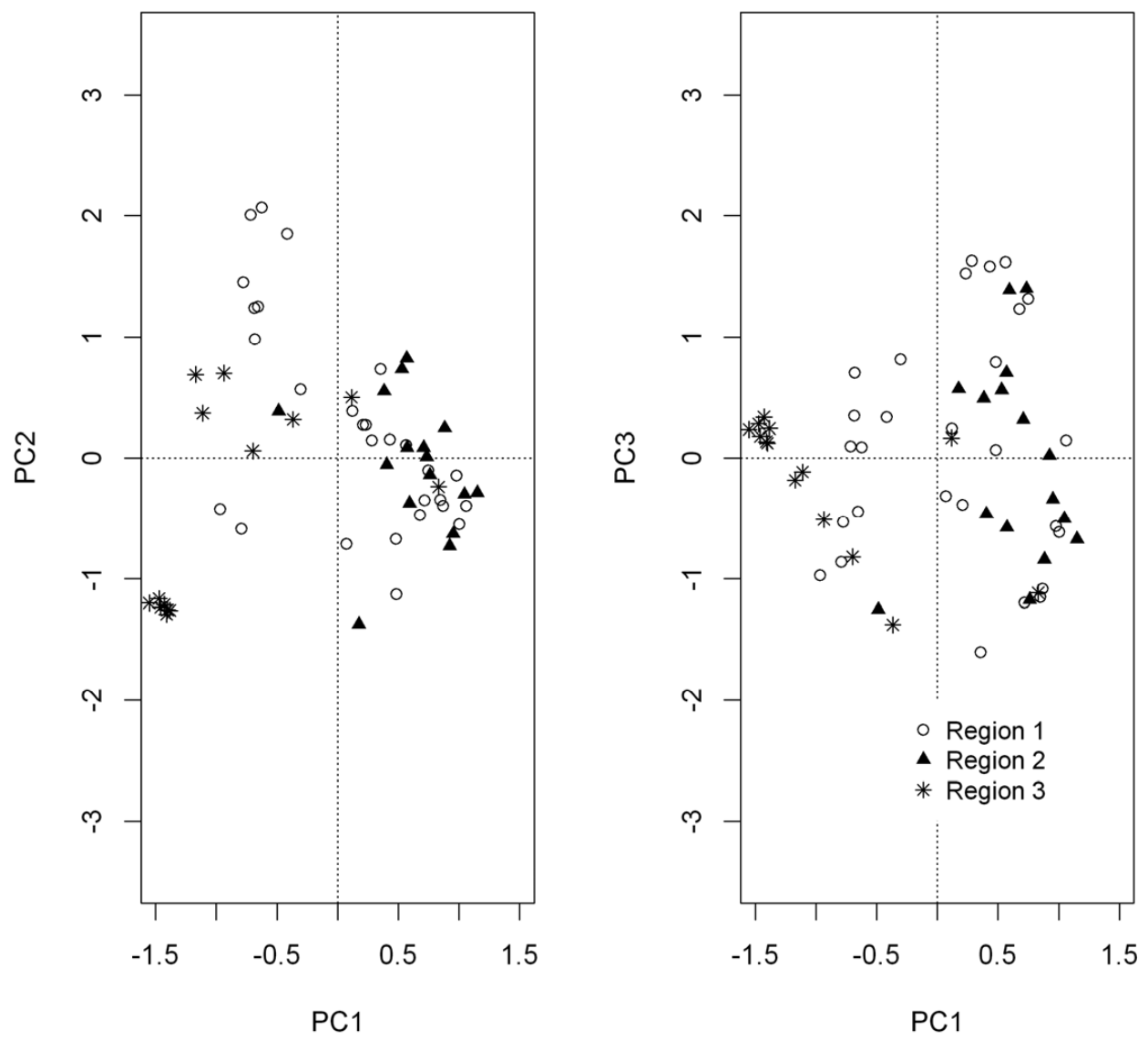

Fig. 2. Principal component analysis plot for Plasmodiophora field isolates. Projection of the first three axes (PC1 to PC3). Percentage of variation explained by the axes: 21,11 , and $9 \%$. 
the 0.01 confidence level (Table 6), confirming geographic clustering between North and South Germany by PCA.

In addition to the distance-based approach (AMOVA), we used a model-based approach (GLM) to test geographic differentiation of the 59 Plasmodiophora field isolates. Spatial variables were associated with the multivariate genetic data. Field $(P=0.003)$ and region $(P=0.001)$ provided the best fit to the data. The field was the most significant predictor of genetic variation. If the model was fitted without field isolates of South Germany, even the field isolates from region 1 and region 2 within North Germany were significantly different $(P=0.015)$ and the field $(P=$ 0.002 ) had a significant effect on the genotypes, explaining most of the genetic variation.

\section{DISCUSSION}

In characterizing the genetic structure of $P$. brassicae populations of three regions in Germany that differ in oilseed rape cropping history, oilseed rape acreage, and infestation levels with $P$. brassicae, we intended to demonstrate that these differences in agricultural ecosystems influence pathogen diversity and population structure. In our study, the AFLP genotypes resulted in distinct field isolates, suggesting that $P$. brassicae is a genetically diverse species, and differentiated two major genetic groups in $P$. brassicae isolates according to their geographic origin.

Gene diversity. Gene diversity estimates for populations studies vary depending on the type of marker and collection methods (45). Therefore, we can compare our results only with a handful of pathogens that were genetically characterized by AFLP markers and sampled with a comparable procedure. Nei's gene diversity of $P$. brassicae populations was moderately high, with $\hat{h}=$ 0.27 on average, and similar to those of other plant pathogens with a complex life cycle. For example, Colletotrichum sublineolum populations had a gene diversity of 0.14 to 0.23 , with a mean of 0.19 (8). The gene diversity of Aphanomyces euteiches populations was 0.2 (22) and of Pythium irregulare populations was 0.26 (20). Mutation is the main source of gene diversity and creates new virulent strains (38). High gene diversity indicates high levels of mutation rates in the life cycle of Plasmodiophora brassicae. The gene diversity is maximized when a population has many alleles at equal frequencies. AFLP marker systems can only detect two alleles (band presence and band absence). Hence, differences in gene diversity arise only from differences in allele frequency, with the consequence that gene diversity in the AFLP marker system is underestimated. High levels of genetic diversity of plant pathogens in agricultural ecosystems can be explained by constant host availability, their ability to infect numerous hosts (50), or the survival as resting spores between host growing seasons. $P$. brassicae has a high reproduction rate; per generation, lasting $\approx 6$ weeks, the inoculum increases by the factor $10^{5}(10)$. The persistence of the resting spores (52) combined with this high reproduction rate can explain the maintenance of large effective population sizes. A large effective population size has a strong influence on overall levels of genetic diversity (9) and may have resulted in highly diverse $P$. brassicae genotypes. Gene diversity is also influenced by the age of the population. We compared the pathogenic structure in North Germany, where cultivation of $B$. napus and the presence of $P$. brassicae were $>150$ years old, with that of South Germany, where oilseed rape was introduced $\approx 25$ years ago. In our study, the gene diversity in North Germany is

TABLE 5. Genetic distances between and within field isolates from regions 1, 2 , and 3

\begin{tabular}{lccc}
\hline & Region 1 & Region 2 & Region 3 \\
\hline Region 1 & 0.60 & 0.61 & 0.66 \\
Region 2 & 0.61 & 0.56 & 0.71 \\
Region 3 & 0.66 & 0.71 & 0.45 \\
\hline
\end{tabular}

similar to the gene diversity in South Germany ( 0.28 versus 0.27 ). It is surprising that region 2 , a traditional oilseed rape cropping area with high oilseed acreage and the highest incidence of clubroot, has the smallest gene diversity $(0.24)$. We expected that short rotations with susceptible hosts greatly increase soil inoculum density, leading to a higher population size of $P$. brassicae in the longer-established population in region 2 , with the result of a high gene diversity index. The high gene diversity of region 1 $(0.31)$, the other traditional oilseed rape cropping area within North Germany, confirm our hypotheses that short rotations and long-established Plasmodiophora populations resulted in higher gene diversity compared with region $3(0.27)$.

Genotypic diversity. Our observations confirmed previous reports of each Plasmodiophora field isolate having a unique multilocus genotype (34). By Stoddard and Taylor's index $G$, genotypic diversity was $100 \%$ of its maximum possible value, on average, in each region. Differences in genotypes of Plasmodiophora field isolates can be explained by the very restricted dispersal of resting spores. Most of the dispersal events between fields of root- and soil-dwelling pathogens are caused through movement of infested soil (25). Under limited spore dispersal, the fields can be considered to act like ecological islands for $P$. brassicae due to their spatial isolation (known as isolation-bydistance population structure) (57). Consequently, a limited gene flow is expected between fields, especially for fields located far apart, with the consequence that the pathogen populations evolve separately. Populations of the soilborne pathogen A. euteiches were differentiated at regional and field levels, induced through the small genetic neighborhood of A. euteiches, which encompass only one agricultural field (22). Populations of Pythium irregulare were significantly different in their allelic frequencies, implying restricted gene flow among populations (24).

The level of genotypic diversity and LD are two characteristics to determine the extent of clonality and recombination in a pathogen population. Populations with sexual reproduction have a high level of genotypic diversity and a random association of alleles at different loci $(23,39)$, whereas clonal reproduction results in non-random association of alleles (5) that leads to LD in a population. In this study, high levels of genotypic diversity and the absence of clones in the populations indicate that sexual reproduction occurs regularly in the life cycle of Plasmodiophora brassicae. In contrast, significant LD was detected in all regions. LD does not appear among neutral markers in populations with sexual reproduction (48) but LD estimators cannot differentiate between LD caused through clonal reproduction and LD that originates from unrecognized population subdivision (23). Such subdivision can be caused through geographical or temporal population structuring (23) and is very likely for $P$. brassicae with short-distance dispersal and population structures with small neighborhoods. If random mating only occurs within these genetic neighborhoods, then population subdivision will lead to the effect of inbreeding and LD when analyzing different subpopulations as one population (48). The different LD values among the regions may reflect the extent of inbreeding; however, Halkett et al. (23) suggested that LD estimators should only be used to detect recombination and not to quantify its extent. We hypothesize that sexual reproduction or mixed reproductive mode combined with short-distance dispersal and spatially restricted genetic neighborhoods is likely to contribute to the high level of genotypic diversity and LD on a larger spatial scale.

TABLE 6. Population pairwise fixation indices ${ }^{\mathrm{a}}$

\begin{tabular}{llll}
\hline & Region 1 & Region 2 & Region 3 \\
\hline Region 1 & 0.000 & 0.046 & $0.226^{* *}$ \\
Region 2 & 0.046 & 0.000 & $0.359^{* *}$ \\
Region 3 & $0.226^{* *}$ & $0.359^{* *}$ & 0.000 \\
\hline
\end{tabular}

a $* P<0.05 ; * * P<0.01 ; * * * P<0.001$. 
Geographic differentiation. AFLP genotypes from region 1 and region 2 were significantly differentiated by their pairwise $F_{\text {ST }}$ values from region 3 . The overall value of $F_{\text {ST }}$ was high $(>2.25)$ and the value of $\mathrm{Nm}$ low $(<1)$, indicating high geographic differentiation and missing gene flow between the population from North Germany and South Germany. Isolates from region 1 and region 2 within North Germany were not differentiated and showed low values of $F_{\text {ST }}$. Missing genetic differentiation of the AFLP genotypes within North Germany can be caused through rare dispersal events between the fields and a common evolutionary history within the field. The logistic regression analysis revealed that every spatial scale had a significant effect on the multilocus genotype; even within North Germany, region 1 and region 2 were significantly differentiated. Warton et al. (55) developed this GLM for multivariate data, because distance-based approaches (such as AMOVA) confound location and dispersion effects and fail to detect differences expressed by less-variable taxa.

Overall, North Germany and South Germany, reflecting the cropping history, were significantly differentiated by distancebased and model-based approaches. Logistic regression analysis revealed that the field $(P=0.003)$ had a significant effect on the multilocus genotype prevalent on the field, indicating small genetic neighborhoods (57). These neighborhoods encompassed only one field, suggesting that field isolates of $P$. brassicae represent a discrete pathogen population. The extent of genetic neighborhood is affected by the method of dispersal of propagative units of a pathogen (38). Agricultural ecosystems induce directional selection on pathogen population due to environmental changes through cultural practices such as cropping resistant cultivars or crop rotations (36). Different cultural practices in North and South Germany may have induced evolution of a neutral DNA marker in Plasmodiophora field isolates. Therefore, similar cultural practices and similar soil climate characteristics within the geographic regions may have a unifying force on the multilocus genotypes of $P$. brassicae leading to relatively more homogeneous genotypes within the regions. Other soilborne pathogens possess population structuring according to their geographic origin. Significant population differentiation and genetic drift through different cultural practices and environmental conditions at the sampling sites has been proposed for the soilborne pathogen Pythium irregulare (24). For C. sublineolum isolates, Chala et al. (8) revealed a differentiation of isolates according to their geographic origin. Most of the variance among P. aphanidermatum was attributable to geographical regions. The four sampling regions are separated from each other by mountains, and ownership and the movement of Pythium inoculum between the regions was limited (2). Population studies of Verticillium dahliae have detected geographic differentiation (4) and a significant effect of agricultural factors on population structure (27). On the other hand, there are soilborne pathogens that prevent geographic structuring because of high migration rates through longdistance dispersal via human transport. The genotypes of the pathogen Phytophthora pisi had no obvious geographic structure. The authors explained this missing structure with the frequent movement of agricultural machinery and root crops in the sampling area (25). Mammella et al. (32) explained the absence of geographic structuring of $P$. nicotianae isolates from different locations with a migration of infected plant material. Nursery trade may be one of the main mechanisms in spreading of Phytophthora inoculum. The results of the PCA revealed that Plasmodiophora field isolates from the same region occasionally failed to cluster in one distinct group. Further, these genotype profiles were assigned to geographically distant regions. This indicates that intermixing of isolates from different geographic regions was attributable to anthropogenic gene flow where, under natural conditions, barriers prevented gene flow (31).

In conclusion, Plasmodiophora brassicae field isolates from Germany were highly differentiated for AFLP genotypes. The high diversity may be a result of high mutation rates, sexual recombination, and large effective population sizes. Every field isolate represents a discrete population and no genotype flow was detected between single fields. In addition, the field isolates were differentiated according to their geographic origin; similar cultural practices and similar environmental characteristics within the geographic regions may have a unifying force on the multilocus genotypes. Further comparison of European-wide P. brassicae populations for AFLP genotypes, including environmental data, may provide new insights into the origin of the German genotypes and the effect of the environment on the evolution of a neutral DNA marker (33). With regard to local scale (one field), research of population genetics would allow to determine the extent of sexual recombination and clonal reproduction in the life cycle of $P$. brassicae.

\section{ACKNOWLEDGMENTS}

We thank E. Diederichsen and U. Preiss for the supply of Plasmodiophora field isolates. E. Diederichsen also provided helpful comments on the manuscript. Particular thanks to R. Horn for her valuable input and the possibility of using the LI-COR 4300 DNA sequencer. This study was cofunded by the Evangelisches Studienwerk Villigst.

\section{LITERATURE CITED}

1. Agapow, P.-M., and Burt, A. 2001. Indices of multilocus linkage disequilibrium. Mol. Ecol. Notes 1:101-102.

2. Al-Sadi, A. M., Drenth, A., Deadman, M. L., and Aitken, E. A. B. 2008. Genetic diversity, aggressiveness and metalaxyl sensitivity of Pythium aphanidermatum populations infecting cucumber in Oman. Plant Pathol. 57:45-56.

3. Anonymous. 2012. Statistisches Bundesamt; Landwirtschaftliche Bodennutzung-Anbau auf dem Ackerland-Fachserie 3 Reihe 3.1.2-Vorbericht 2012.

4. Atallah, Z. K., Maruthachalam, K., Toit, L. D., Koike, S. T., Michael Davis, R., Klosterman, S. J., Hayes, R. J., and Subbarao, K. V. 2010. Population analyses of the vascular plant pathogen Verticillium dahliae detect recombination and transcontinental gene flow. Fungal Genet. Biol. 47:416-422.

5. Awadalla, P. 2003. The evolutionary genomics of pathogen recombination. Nat. Rev. Genet. 4:50-60.

6. Braselton, J. P. 1981. Karyotypic analysis of Plasmodiophora brassicae based on serial thin sections of pachytene nuclei. Can. J. Bot. 60:403-408.

7. Buhariwalla, H., Greaves, S., Magrath, R., and Mithen, R. 1995. Development of specific primers for the amplification of polymorphic DNA from the obligate root pathogen Plasmodiophora brassicae. Physiol. Mol. Plant Pathol. 47:83-94.

8. Chala, A., Tronsmo, A. M., and Brurbergbc, M. B. 2011. Genetic differentiation and gene flow in Colletotrichum sublineolum in Ethiopia, the centre of origin and diversity of sorghum, as revealed by AFLP analysis. Plant Pathol. 60:474-482.

9. Criscione, C. D., Poulin, R., and Blouin, M. S. 2005. Molecular ecology of parasites: elucidating ecological and microevolutionary processes. Mol. Ecol. 14:2247-2257.

10. Diederichsen, E., Frauen, M., Linders, E. G. A., Hatakeyama, K., and Hirai, M. 2009. Status and perspectives of clubroot resistance breeding in crucifer crops. J. Plant Growth Regul. 28:265-281.

11. Dixon, G. R. 2009. The occurrence and economic impact of Plasmodiophora brassicae and clubroot disease. J. Plant Growth Regul. 28:194-202.

12. Donald, C., and Porter, I. 2009. Integrated control of clubroot. J. Plant Growth Regul. 28:289-303.

13. Donald, E. C., Cross, S. J., Lawrence, J. M., and Porter, I. J. 2006. Pathotypes of Plasmodiophora brassicae, the cause of clubroot, in Australia. Ann. Appl. Biol. 148:239-244.

14. Dray, S., and Dufour, A. B. 2007. The ade 4 package: implementing the duality diagram for ecologists. J. Stat. Software 22:1-20.

15. Ehrich, D. 2006. Aflpdat: a collection of $\mathrm{R}$ functions for convenient handling of AFLP data. Mol. Ecol. Notes 6:603-604.

16. Excoffier, L., and Lischer, H. E. L. 2010. Arlequin suite version 3.5: A new series of programs to perform population genetics analyses under Linux and Windows. Mol. Ecol. Resources 10:564-567.

17. Fähling, M., Graf, H., and Siemens, J. 2003. Pathotype separation of Plasmodiophora brassicae by the host plant. J. Phytopathol. 151:425-430.

18. Fähling, M., Graf, H., and Siemens, J. 2004. Characterization of a single- 
spore isolate population of Plasmodiophora brassicae resulting from a single club. J. Phytopathol. 152:438-444.

19. Garber, R. C., and Aist, J. R. 1979. The ultrastructure of meiosis in Plasmodiophora brassicae (Plasmodiophorales). Can. J. Bot. 57:2509-2518.

20. Garzón, C. D., Geiser, D. M., and Moorman, G. W. 2005. Amplified fragment length polymorphism analysis and internal transcribed spacer and coxII sequences reveal a species boundary within Pythium irregulare. Plant Dis. 89:81-89.

21. Grünwald, N. J., Goodwin, S. B., Milgroom, M. G., and Fry, W. E. 2003. Analysis of genotypic diversity data for populations of microorganisms. Phytopathology 93:738-746.

22. Grünwald, N. J., and Hoheisel, G.-A. 2006. Hierarchical analysis of diversity, selfing, and genetic differentiation in populations of the oomycete Aphanomyces euteiches. Phytopathology 96:1134-1141.

23. Halkett, F., Simon, J.-C., and Balloux, F. 2005. Tackling the population genetics of clonal and partially clonal organisms. Trends Ecol. Evol. 20:194-201.

24. Harvey, P. R., Butterworth, P. J., Hawke, B. G., and Pankhurst, C. E. 2000. Genetic variation among populations of Pythium irregulare in Southern Australia. Plant Pathol. 49:619-627.

25. Heyman, F., Blair, J. E., Persson, L., and Wikström, M. 2013. Root rot of pea and faba bean in southern Sweden caused by Phytophthora pisi sp. nov. Plant Dis. 97:461-471.

26. Ingram, D. S., and Tommerup, I. C. 1972. The life history of Plasmodiophora brassicae Wor. Proc. R Soc. Lond. 180:103-112.

27. Jiménez-Díaz, R. M., Olivares-García, C., Landa, B. B., del Mar JiménezGasco, M., and Navas-Cortés, J. A. 2011. Region-wide analysis of genetic diversity in Verticillium dahliae populations infecting olive in Southern Spain and agricultural factors influencing the distribution and prevalence of vegetative compatibility groups and pathotypes. Phytopathology 101:304-315.

28. Kageyama, K., and Asano, T. 2009. Life cycle of Plasmodiophora brassicae. J. Plant Growth Regul. 28:203-211.

29. Klewer, A., Luerßen, H., Graf, H., and Siemens, J. 2001. Restriction fragment length polymorphism markers to characterize Plasmodiophora brassicae single-spore isolates with different virulence patterns. J. Phytopathol. 149:121-127.

30. Kuginuki, Y., Yoshikawa, H., and Hirai, M. 1999. Variation in virulence of Plasmodiophora brassicae in Japan tested with clubroot-resistant cabbage cultivars (Brassica rapa L. ssp. pekinensis). Eur. J. Plant Pathol. 105:327332.

31. Leisova-Svobodova, L., Matusinsky, P., and Kucera, L. 2012. Variability of the Ramularia collo-cygni population in Central Europe. J. Phytopathol. 160:701-709.

32. Mammella, M.-A., Martin, F. N., Cacciola, S. O., Coffey, M., Faedda, R., and Schena, L. 2013. Analyses of the population structure in a global collection of Phytophthora nicotianae isolates inferred from mitochondrial and nuclear DNA sequences. Phytopathology 103:610-622.

33. Manel, S., Joost, S., Epperson, B. K., Holderegger, R., Storfer, A., Rosenberg, M. S., Scribner, K. T., Bonin, A., and Fortin, M. J. 2010. Perspectives on the use of landscape genetics to detect genetic adaptive variation in the field. Mol. Ecol. 19:3760-3772.

34. Manzanares-Dauleux, M. J., Divaret, I., Baron, F., and Thomas, G. 2001. Assessment of biological and molecular variability between and within field isolates of Plasmodiophora brassicae. Plant Pathol. 50:165-173.

35. McDermott, J. M., and McDonald, B. A. 1993. Gene flow in plant pathosystems. Annu. Rev. Phytopathol. 31:353-373.

36. McDonald, B. A. 1997. The population genetics of fungi: Tools and techniques. Phytopathology 87:448-452.

37. McDonald, B. A., and Linde, C. 2002. Pathogen population genetics, evolutionary potential, and durable resistance. Annu. Rev. Phytopathol.
40:349-379.

38. McDonald, B. A., and Linde, C. 2002. The population genetics of plant pathogens and breeding for durable resistance. Euphytica 12:163-180.

39. Milgroom, M. G. 1996. Recombination and the multilocus structure of fungal populations. Annu. Rev. Phytopathol. 34:457-477.

40. Möller, M., and Harling, R. 1996. Randomly amplified polymorphic DNA (RAPD) profiling of Plasmodiophora brassicae. Lett. Appl. Microbiol. 22:70-75.

41. Nei, M. 1987. Molecular Evolutionary Genetics. Columbia University Press, New York.

42. Niwa, R., Kawahara, A., Murakami, H., Tanaka, S., and Ezawa, T. 2011. Complete structure of nuclear rDNA of the obligate plant parasite Plasmodiophora brassicae: intraspecific polymorphisms in the exon and group I intron of the large subunit rDNA. Protist 162:423-434.

43. Oksanen, J., Blanchet, F. G., Kindt, R., Legendre, P., Minchin, P. R., O'Hara, R. B., Simpson, G. L., Solymos, P., Stevens, M. H. H., and Wagner, H. 2012. Vegan: Community Ecology Package. R package version 2.0-4. http://CRAN.R-project.org/package=vegan

44. Rennie, D. C., Manolii, V. P., Cao, T., Hwang, S. F., Howard, R. J., and Strelkov, S. E. 2011. Direct evidence of surface infestation of seeds and tubers by Plasmodiophora brassicae and quantification of spore loads. Plant Pathol. 60:811-819.

45. Rosewich, U. L., Pettway, R. E., McDonald, B. A., Duncan, R. R., and Frederiksen, R. A. 1998. Genetic structure and temporal dynamics of a Colletotrichum graminicola population in a sorghum disease nursery. Phytopathology 88:1087-1093.

46. Somé, A., Manzanares, M. J., Laurens, F., Baron, F., Thomas, G., and Rouxel, F. 1996. Variation for virulence on Brassica napus L. among Plasmodiophora brassicae collections from France and derived singlespore isolates. Plant Pathol. 45:432-439.

47. Strelkov, S. E., Manolii, V. P., Cao, T., Xue, S., and Hwang, S. F. 2007. Pathotype classification of Plasmodiophora brassicae and its occurrence in Brassica napus in Alberta. Canada. J. Phytopathol. 155:706-712.

48. Talbot Brewer, M., Frenkel, O., and Milgroom, M. G. 2012. Linkage disequilibrium and spatial aggregation of genotypes in sexually reproducing populations of Erysiphe necator. Phytopathology 102:997-1005.

49. Tommerup, I. C., and Ingram, I. C. 1971. The life-cycle of Plasmodiophora brassicae Woron. in Brassica tissue cultures and in intact roots. New Phytol. 70:327-332.

50. Travadon, R., Sache, I., Dutech, C., Stachowiak, A., Marquer, B., and Bousset, L. 2011. Absence of isolation by distance patterns at the regional scale in the fungal plant pathogen Leptosphaeria maculans. Fungal Biol. 115:649-659.

51. Vos, P., Hogers, R., Bleeker, M., Reijans, M., van de Lee, T., Hornes, M., Frijters, A., Pot, J., Peleman, J., and Kuiper, M. 1995. AFLP: A new technique for DNA fingerprinting. Nucleic Acids Res. 23:4407-4414.

52. Wallenhammar, A.-C. 1996. Prevalence of Plasmodiophora brassicae in a spring oilseed rape growing area in central Sweden and factors influencing soil infestation level. Plant Pathol. 45:710-719.

53. Wang, Y., Naumann, U., Wright, S. T., and Warton, D. I. 2012. mvabund: Statistical Methods for Analysing Multivariate Abundance Data. R package version 3.1. http://CRAN.R-project.org/package $=$ mvabund

54. Wang, Y., Naumann, U., Wright, S. T., and Warton, D. I. 2012. mvabund-an $\mathrm{R}$ package for model-based analysis of multivariate abundance data. Methods Ecol. Evol. 3:471-474.

55. Warton, D. I., Wright, S., and Wang, Y. 2012. Distance-based multivariate analyses confound location and dispersion effects. Methods Ecol. Evol. 3:89-101.

56. Whitlock, M. C., and McCauley, D. E. 1999. Indirect measure of gene flow and migration. Heredity 82:117-25.

57. Wright, S. 1943. Isolation by distance. Genetics 28:114-138. 